\title{
Venous thromboembolism prophylaxis post-discharge in hip fracture surgery patients: what to do if the patient is taking antiplatelets
}

\author{
Authors: Andrew Porter, Shuli Levy and Michael Fertleman
}

\section{Aims}

To assess whether adequate post-discharge venous thromboembolism (VTE) prophylaxis is prescribed to patients who underwent hip fracture surgery (HFS) and to consider what should be prescribed to patients who are already taking antiplatelet agents.

\section{Methods}

A retrospective study analysed discharge prescriptions of HFS patients at a London teaching hospital over a 10 -week period. Both anticoagulant and antiplatelet prescriptions were recorded. A re-audit was then carried out again over a 10 -week period.

\section{Results}

In the initial audit, 40 patients had HFS and had been discharged with a completed discharge prescription. The repeat audit included 41 patients. The results are shown in the table below.

\section{Conclusions}

Owing to the high risk of VTE post-HFS, it is important that appropriate prophylaxis is given and continued post-discharge. NICE advises Fondaparinux or low-molecular-weight heparin (LMWH) for a total of 28-35 days. The American College of Chest Physicians recommends LMWH for 28-35 days or a novel oral anticoagulant for those unable to cooperate with daily injections.
Analysis of our initial results demonstrated poor compliance with these guidelines, partly owing to inadequate guidance on what to prescribe to those taking single or dual antiplatelet therapy. A literature review found no relevant evidence-based guidelines. We therefore created new guidelines based on the consensus opinion of the trust VTE task force, as follows.

> Patients taking single antiplatelet therapy should also receive rivaroxiban for 5 weeks.

> Those taking dual antiplatelet therapy should not receive additional thromboprophylaxis owing to increased bleeding risk.

$>$ Those on warfarin require no added prophylaxis.

Using this, 34\% of patients in the initial audit and 56\% in the re-audit received adequate post-discharge VTE prophylaxis. More should be done to ensure that appropriate prophylaxis is prescribed and guidelines should be updated to include recommendations on prophylaxis in patients taking antiplatelets.

\section{Conflict of interest statement}

There was no conflict of interest in this audit.

\section{Table 1. VTE prophylaxis post-discharge.}

\begin{tabular}{|c|c|c|c|c|c|c|c|c|c|}
\hline \multicolumn{6}{|c|}{ Adequate VTE prophylaxis } & \multicolumn{4}{|c|}{ Inadequate VTE prophylaxis } \\
\hline \multicolumn{2}{|c|}{$\begin{array}{l}\text { Patients discharged on } \\
\text { anticoagulant }\end{array}$} & \multicolumn{2}{|c|}{$\begin{array}{l}\text { Patients discharged on } \\
\text { single antiplatelet and } \\
\text { anticoagulant }\end{array}$} & \multicolumn{2}{|c|}{$\begin{array}{l}\text { Patients discharged on } \\
\text { dual antiplatelet }\end{array}$} & \multicolumn{2}{|c|}{$\begin{array}{l}\text { Patients discharge on } \\
\text { a single antiplatelet }\end{array}$} & \multicolumn{2}{|c|}{$\begin{array}{l}\text { Patients discharged with } \\
\text { no anticoagulant and no } \\
\text { antiplatelet agents }\end{array}$} \\
\hline Initial audit & Re-audit & Initial audit & Re-audit & Initial audit & Re-audit & Initial Audit & Re-audit & Initial audit & Re-audit \\
\hline $12^{a}$ & $14^{a}$ & $1^{a}$ & $9^{a}$ & $1^{a}$ & $0^{a}$ & $9^{a}$ & $7^{a}$ & $17^{a}$ & $11^{a}$ \\
\hline $30 \%$ & $34 \%$ & $2 \%$ & $22 \%$ & $2 \%$ & $0 \%$ & $23 \%$ & $17 \%$ & $43 \%$ & $27 \%$ \\
\hline
\end{tabular}

